\title{
Application of Mössbauer spectroscopy for classification of ordinary chondrites - different database and different methods
}

\author{
Jolanta Gałązka-Friedman ${ }^{1}$ • Marek Woźniak ${ }^{2}$ • Patrycja Bogusz ${ }^{1}$ • \\ Martyna Jakubowska ${ }^{1} \cdot$ Łukasz Karwowski $^{3} \cdot$ Przemysław Duda $^{1}$
}

Published online: 17 December 2019

(C) The Author(s) 2019

\begin{abstract}
Classification of the meteorites is very complex, but in general all meteorites can be divided into three groups: stony, iron and stony-iron. Ordinary chondrites are the most numerous group among stony meteorites. In this paper, we present short review of the methods of classification of ordinary chondrites. The classical method for the classification of ordinary chondrites is based on the determination of the content of fayalite in olivine and of the content of ferrosilite in pyroxene with the use of electron microprobe. This method was proposed in 1967. Studies on the application of Mössbauer spectroscopy to classification of ordinary chondrites were carried out since early 2000 in four Mössbauer laboratories. Mössbauer groups from Kanpur, Ekaterinburg and Canberra suggested qualitative methods of classification of ordinary chondrites. Warsaw group created quantitative method called the "4M method". This name derives from following words: meteorites, Mössbauer spectroscopy, multidimensional discriminant analysis, Mahalanobis distance. In this publication, we describe the use of $4 \mathrm{M}$ method for reclassification of meteorite Goronyo.
\end{abstract}

Keywords Classification of meteorites · Ordinary chondrites · Mössbauer spectroscopy Multidimensional discriminant analysis $\cdot$ Mahalanobis distance $\cdot$ Meteorite Goronyo

This article is part of the Topical Collection on Proceedings of the 5th Mediterranean Conference on the Applications of the Mössbauer Effect (MECAME 2019) and 41st Workshop of the French-speaking Group of Mössbauer Spectroscopy (GFSM 2019), Montpellier, France, 19-23 May 2019

Edited by Pierre-Emmanuel Lippens, Yann Garcia, Moulay-Tahar Sougrati and Mira Ristic $(\dagger)$

Jolanta Gałązka-Friedman

jolanta.friedman@pw.edu.pl

1 Faculty of Physics, Warsaw University of Technology, Koszykowa 75, 00-662 Warsaw, Poland

2 Faculty of Biology, University of Warsaw, Miecznikowa 1, 02-096 Warszawa, Poland

3 Faculty of Earth Sciences, University of Silesia in Katowice, ul. Będzińska 60, 41-200 Sosnowiec, Poland 


\section{Introduction}

Ordinary chondrites account for more than $80 \%$ of meteoritic falls. The common feature of all ordinary chondrites is presence in their interior of so called chondrules. They are spherical pieces of meteorite material. The size of the chondrules ranges from few micrometers to over one centimeter. Publication by Knudsen [1] provides more information and pictures the surface of a meteorite covered by numerous chondrules. There are three types of ordinary chondrites: type H (high iron), type L (low iron) and type LL (low iron, low metal). The main mineralogical phases present in ordinary chondrites are: olivine, pyroxene, metallic phases and troilite. Figure 1 shows Mössbauer spectra of ordinary chondrites type H, L and LL.

When looking at the spectra presented above, a perceptive reader might be able to determine the type of the presented meteorite. This observation has laid the groundwork for creation of a novel method of classification of ordinary chondrites, based only on percentages of Mössbauer spectral areas. First papers discussing this subject were published at the beginning of XXI century by H.C. Verma group from Kanpur [2-4]. The idea of Verma group was explored by other Mössbauer groups.

In this paper we will discuss chemical and mineralogical composition of ordinary chondrites as well as the classical method of classification of these meteorites. Next we will review the properties of databases and methods used for the classification of ordinary chondrites by four groups based in Kanpur, Ekaterinburg, Canberra and Warsaw. To conclude, we will summarize the properties of meteoritic samples that they should possess in order to be classifiable with the use of $4 \mathrm{M}$ method proposed by the Warsaw group.

\section{The chemical and mineralogical composition of ordinary chondrites and the classical method of their classification}

Ordinary chondrites are not a homogeneous group of meteorites. They differ in chemical composition and petrologic structure.

Four iron-bearing mineralogical phases: olivines, pyroxenes, metallic phase in the form of Fe-Ni alloy and iron sulfide - troilite, present in ordinary chondrites constitute over $95 \%$ of its total composition.

In chondrites, iron occurs in all possible oxidation states:

- $\quad \mathrm{Fe}^{0}$, metal - as grains and veins of Fe-Ni alloy (in all types of chondrites, excluding carbonaceous chondrites, in which it is a very rare phase). Iron in 0 state of oxidation is present in following minerals: kamacite and taenite;

- $\mathrm{Fe}^{2+-}$ as a component of many minerals; in all stone meteorites it forms ferrous silicates olivine (fayalite) and pyroxene (ferrosilite), as grains and nodules of troilite (FeS) and also in minerals: chromite, ilmenite, pyrrhotite, wustite;

- $\mathrm{Fe}^{3+-}$ in a form of rare iron oxide (magnetite), and also as a component of secondary minerals that are products of weathering of meteorites (akaganeite, goethite).

The classical method for determining the type of ordinary chondrite is based on measurements of the content of fayalite $(\mathrm{Fa})$ in olivine and the content of ferrosilite $(\mathrm{Fs})$ in orthopyroxenes.

Olivines are a group of silicates $(\mathrm{Fe}, \mathrm{Mg})\left[\mathrm{SiO}_{4}\right]$ forming a continuous isomorphic series: fayalite $\left(\mathrm{Fa} ; \mathrm{Fe}\left[\mathrm{SiO}_{4}\right]\right)$ - forsterite (Fo; $\left.\mathrm{Mg}\left[\mathrm{SiO}_{4}\right]\right)$ (Fig. 2). 
a

BASSIKOUNOU

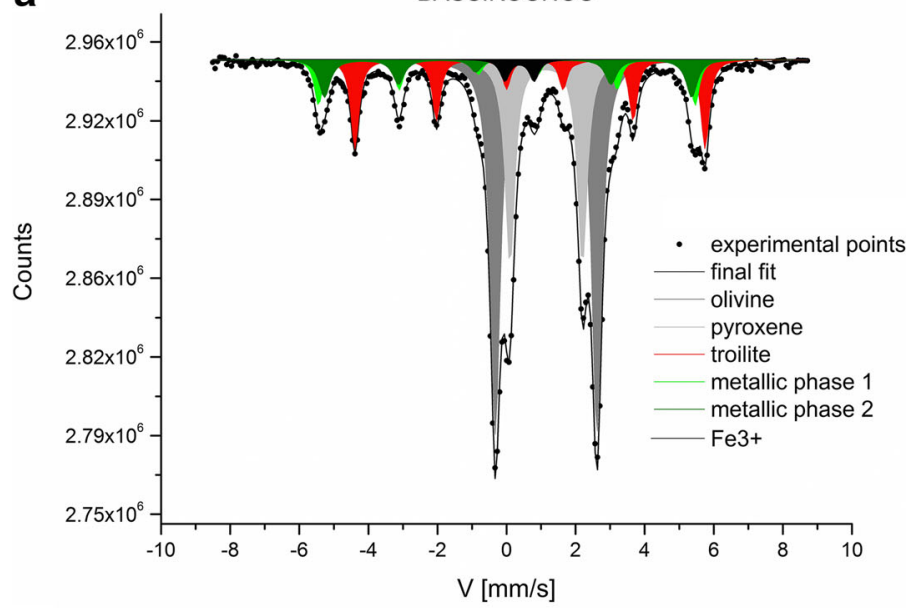

b

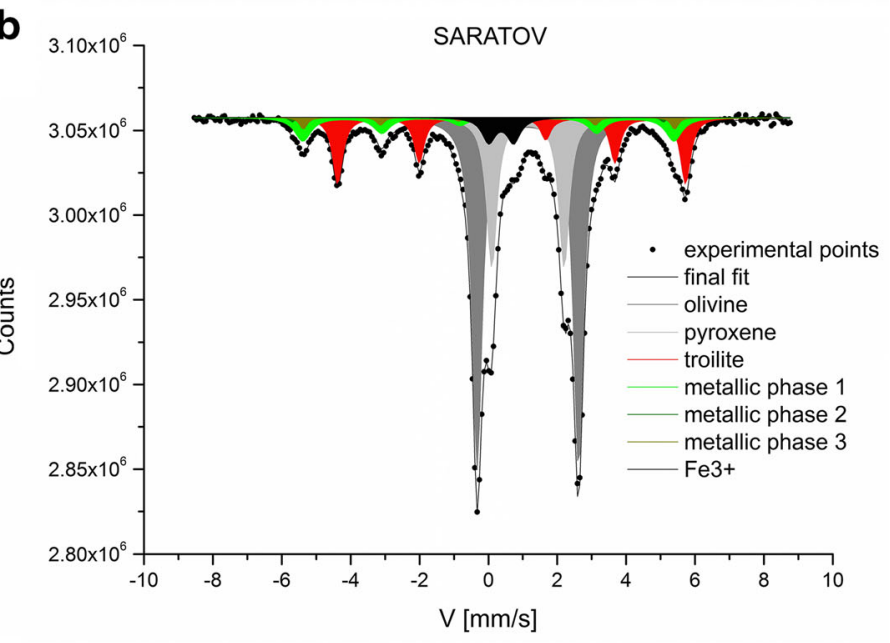

C

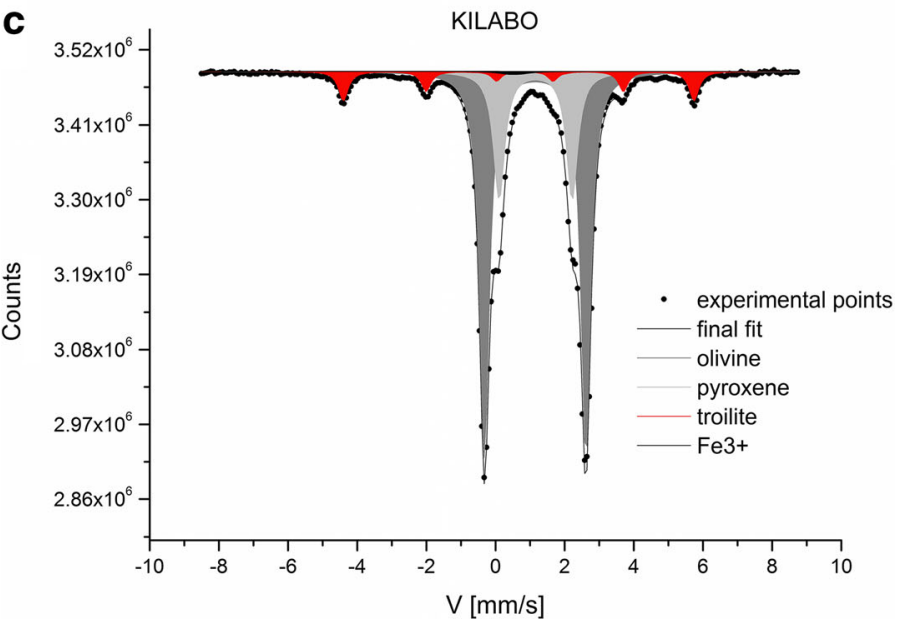

Fig. 1 Mössbauer spectra of ordinary chondrites type H (Bassikounou), type L (Saratov), type LL (Kilabo) 


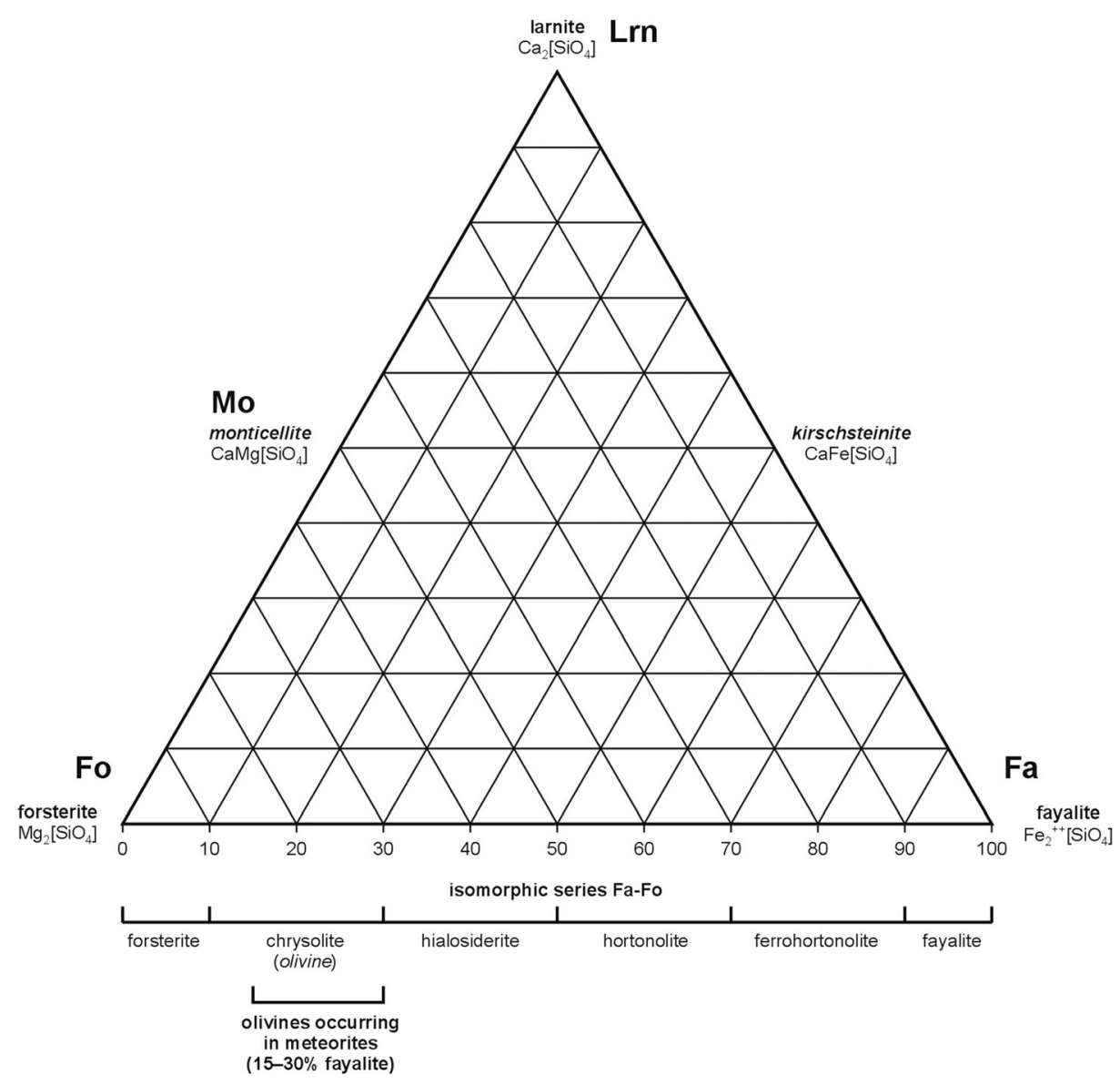

Fig. 2 Isomorphic series of olivines

Pyroxenes are minerals with the general formula: $\mathrm{AB}\left[\mathrm{Si}_{2} \mathrm{O}_{6}\right]$, where $\mathrm{AB}$ positions can be occupied by: $\mathrm{Mg}_{2},(\mathrm{MgFe})_{2}, \mathrm{Fe}_{2}$. In ordinary chondrite predominate the rhombic pyroxenes (orthopyroxenes) - they form a continuous isomorphic series: enstatite (En; $\mathrm{Mg}_{2}\left[\mathrm{Si}_{2} \mathrm{O}_{6}\right]$ ) - ferrosilite (Fs; $\left.\mathrm{Fe}_{2}\left[\mathrm{Si}_{2} \mathrm{O}_{6}\right]\right)$ (Fig. 3).

Prior's observation [5] that "the less the amount of nickel-iron in chondritic stones (...) the richer in iron are the magnesium silicate" served as the basis for the introduction of mineralogical classification of ordinary chondrites. Subsequently, this observation was developed further by Mason [6].

Chemical analysis of silicates isolated from 95 equilibrated ordinary chondrites (petrologic type 4 and more) with an electron microprobe was used for the first time by 1964 Keil and Fredriksson [7]. They determined the content of iron in the main silicate minerals. These results clearly confirmed the presence of three groups of ordinary chondrites - H, L and LL.

The current (chemical-petrologic) division of chondrites was proposed in 1967 by W.R. Van Schmus and J.D. Wood [8]. This method is based on the differences in the chemical compositions and in the iron amounts. This division was developed on the basis 


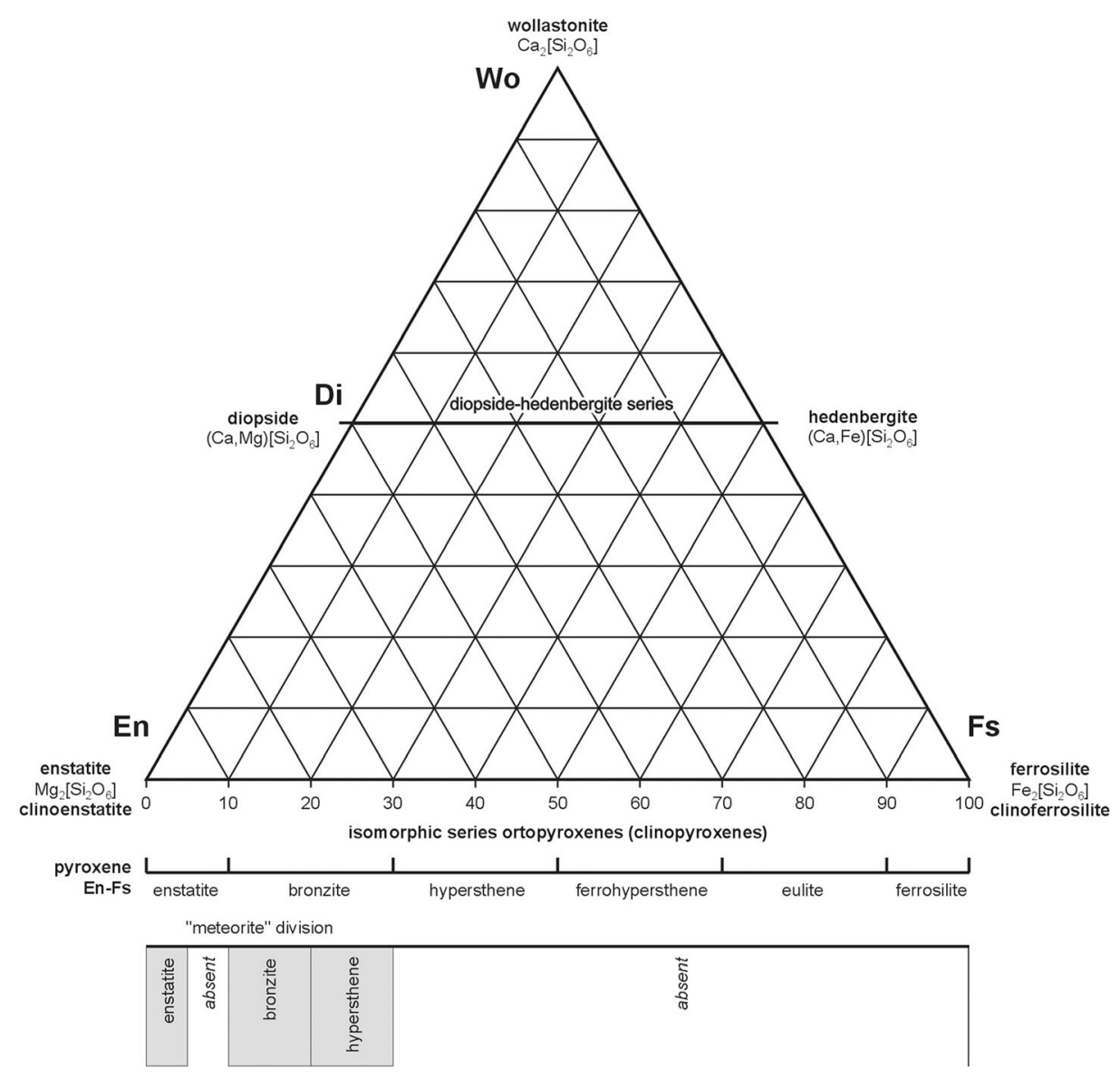

Fig. 3 Isomorphic series of pyroxenes

of earlier classification method of chondrites by Prior and Mason [5, 6]. In Van Schmus classification, other properties of ordinary chondrites were also applied: relationships between the main mineral-forming elements of chondrites: $\mathrm{Mg}, \mathrm{Ca}$ and $\mathrm{Al}$, a presence of the chromite as well as values of the ratio of the oxygen isotope $(16,17,18 \mathrm{O})$. Van Schmus and Wood noticed five different types of chondrite: E, H, L, LL and C. Type R (rumuruti) was added later. The current division of chondrites into 6 petrologic groups has also been previously suggested by these two scientists.

Figure 4 shows the plot of the ferrosilite (Fs) content in orthopyroxenes versus fayalite (Fa) content in olivine for ordinary chondrites, which were classified in the Meteoritical Bulletin database. In classical method, the ratio of these two silicate phases served as the criterion for qualifying ordinary chondrite into one of three types: H, L, LL.

In the Mössbauer studies the amount of iron in all mineral phases is determined. Percentages of Mössbauer spectral areas associated with these phases have different, characteristic values for different types of ordinary chondrites. This observation became a starting point for creation of new methods of classification of ordinary chondrites based only on Mössbauer data. 


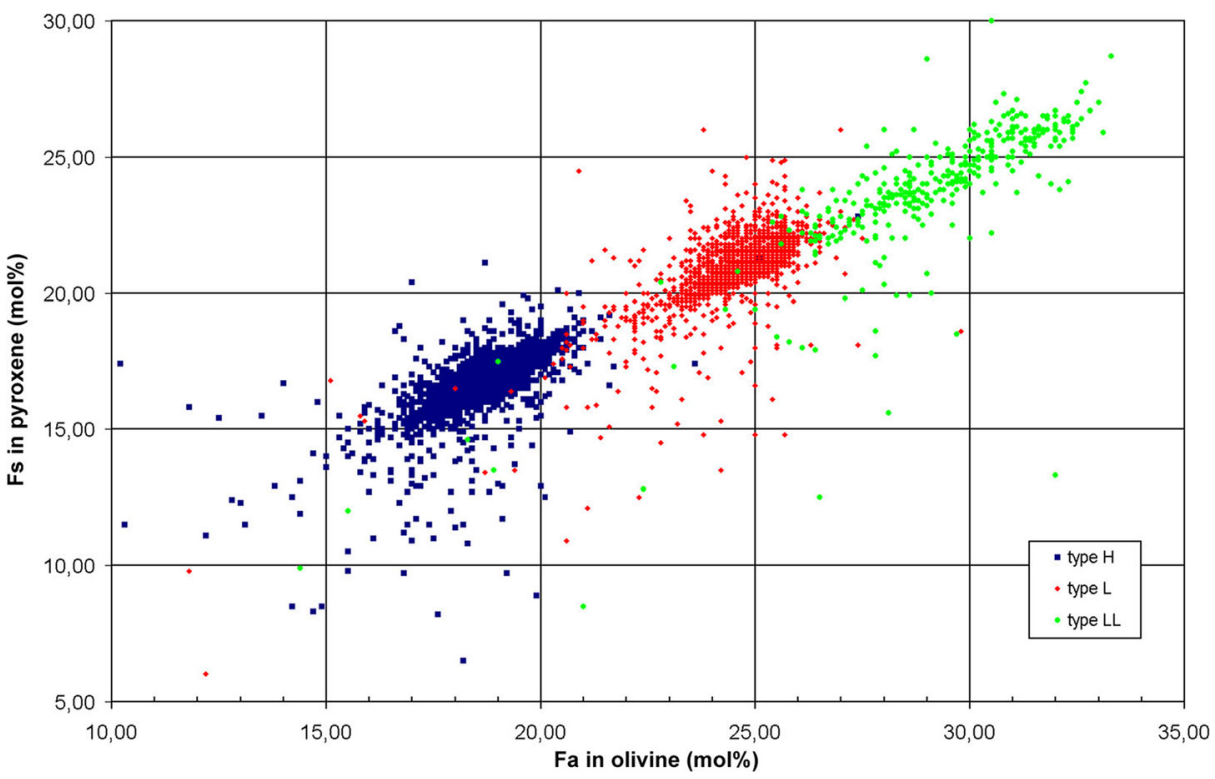

Fig. 4 The content of ferrosilite (Fs) in orthopiroxenes vs. the content of fayalite (Fa) in olivine for ordinary chondrites classified in the Meteoritical Bulletin database. Source Koblitz MetBase

\section{Different Mössbauer databases and different methods applied in different laboratories to determine the types of ordinary chondrite}

\subsection{Mössbauer laboratory in Kanpur}

First database of the Verma group [3] consisted of thirteen Mössbauer spectra of ordinary chondrites (eight ordinary chondrites type $\mathrm{H}$, four ordinary chondrites type L and one ordinary chondrite type L/LL). Seven Mössbauer spectra were obtained in Kanpur and others came from literature review.

On the basis of these data three 2D plots were constructed: metallic phases vs. non-metallic phases, metallic phases vs. silicate phases (olivine + pyroxene) as well as olivine vs. pyroxene. Additionally, one 1D plot depicting the ratio of olivine/pyroxene area was also constructed. In each of these plots the authors observed regions with higher concentration of different types of chondrites. By drawing oblique lines in two plots and perpendicular lines in other two, three regions were determined as arbitrary: REGION I - included ordinary chondrites type $\mathrm{H}$; REGION II - included ordinary chondrites type H and type L/LL; and REGION III - included ordinary chondrites type L/LL. The authors noticed that point representing meteorite ItawaBhopij was always located in Region III.

Second database of the Verma group [4] was composed of the first database and ten new Mössbauer spectra. Therefore, in the second database 24 Mössbauer spectra of ordinary chondrites (eleven chondrites type H, seven chondrites type L, and five chondrites type LL) were present.

Using the second database, two 2D plots were constructed: metallic phases vs. silicate phases (olivine + pyroxene) and pyroxene vs. olivine. One constructed 1D plot depicted the 
ratio of olivine area/pyroxene area. On 2D plots the regions with ellipse shape were arbitrarily determined. On 1D plot three zones were determined. Based on the analysis of the location of the point representing meteorite Jodhpur, it was suggested, that it probably belongs to the group L/LL.

\subsection{Mössbauer laboratory in Ekaterinburg}

In the two databases of the Ekaterinburg group only the Mössbauer spectra obtained in their own laboratory are present. The first database [9] was composed of seven ordinary chondrites type L and four ordinary chondrites type H. In the aforementioned paper [9], four different plots type 2D showing different combinations of spectral areas of olivines, pyroxenes, metallic phases and troilite were presented. In these plots the authors tried to isolate the regions typical for types $\mathrm{H}$ and $\mathrm{L}$ by drawing arbitrary perpendicular lines, but they did not attempt to classify any meteorite.

The second database of Ekaterinburg laboratory [10] consisted of Mössbauer spectra of four ordinary chondrites type $\mathrm{H}$, five ordinary chondrites type $\mathrm{L}$ and five ordinary chondrites type LL. 2D type plot depicting total relative area of metal+oxidized iron vs. relative area of olivine was created. In this plot two perpendicular lines divide space into three regions typical for types H, L and LL. The points representing two meteorites: NWA 6286 and NWA 7857 were located in the region typical for ordinary chondrites type LL.

\subsection{Mössbauer laboratory in Canberra}

Mössbauer group from Canberra [11] decided to use only some of Mössbauer spectra present in Varma database for the classification of Lynch 001 meteorite. The authors presented 3 plots: two 2D plots, one depicting metallic vs. nonmetallic phase, the other depicting metallic vs. silicate phase, as well as one 1D plot of the ratio of olivine area/pyroxene area. In 2D plots two oblique lines divided space into three regions: in Region I only H type, in Region II meteorites $\mathrm{H}$ and $\mathrm{L}$ and in Region III only type $\mathrm{L}$ were observed. In the first 2D plot the meteorite Lynch 001 is located in Region III. The second 2D plot located the meteorite Lynch 001 in Region II. The 1D plot presents the meteorite Lynch 001 in Region III, together with L and LL meteorites. The authors concluded, that the meteorite Lynch 001 belongs to type $\mathrm{L}$ and commented: "Clearly, such classifications do not yield a definitive assignment but nevertheless they do provide a useful picture of the meteorite".

\subsection{Mössbauer laboratory in Warsaw}

In Warsaw group, we have been publishing papers on classification of ordinary chondrites since 2014 [12-19]. The database which we used for the creation of a new, fully quantitative method for classification of ordinary chondrites is composed of 59 Mössbauer spectra (22 type H, 20 type L and 17 type LL (Fig. 5)). 41 spectra were obtained in our laboratory, whereas others came from the literature review. Hence, only the nonweathered or little weathered (paramagnetic doublet of Fe3+ smaller than 7\%) ordinary chondrites' Mössbauer spectra are found in our database. All the results were shown in the supplementary Table 1 as published by Wozniak et al. [19]. In this table, the percentages of spectral area associated with olivine (ol), pyroxene (pyr), metallic phase (met) and troilite (tr) were listed. The results obtained are presented here in ternary plot in Fig. 5. 
The database described above was used to formulate the method to determine the type $(\mathrm{H}, \mathrm{L}$ or LL) of the investigated meteorite. We named it "4M method" and published it earlier this year (Wozniak et al. [19]). The name of this method derives from four words starting with letter M: Meteorites, Mössbauer spectroscopy, Multidimensional discriminant analysis (MDA) and Mahalanobis distance.

Using our database, one cluster (created from Mössbauer spectral areas) was established for each type of ordinary chondrites (H, L and LL). The application of multidimensional discriminant analysis enabled us to calculate Mahalanobis distance from the investigated meteorite to the centroid of all three clusters.

After the calculation of Mahalanobis distance, it became possible to determine the level of similarity $\left(\mathbf{S}_{\text {cluster }}\right.$ ) of the investigated meteorite to the specific cluster. The paper by Woźniak et al. [19] presents the definition of Mahalanobis distance and of the level of similarity.

4M method was tested on meteorite Goronyo with the use of Mössbauer spectral areas measured and calculated by us. The obtained results are presented below:

\begin{tabular}{lccc}
\hline & type $\mathrm{H}$ & type $\mathrm{L}$ & type $\mathrm{LL}$ \\
The Mahalanobis distance $\mathrm{d}_{\mathrm{M}}(4 D)$ & 3.07 & 0.77 & 3.54 \\
The level of the similarity $\mathrm{S}_{\text {cluster }}$ & $31.6 \%$ & $74.7 \%$ & $10.6 \%$ \\
\hline
\end{tabular}

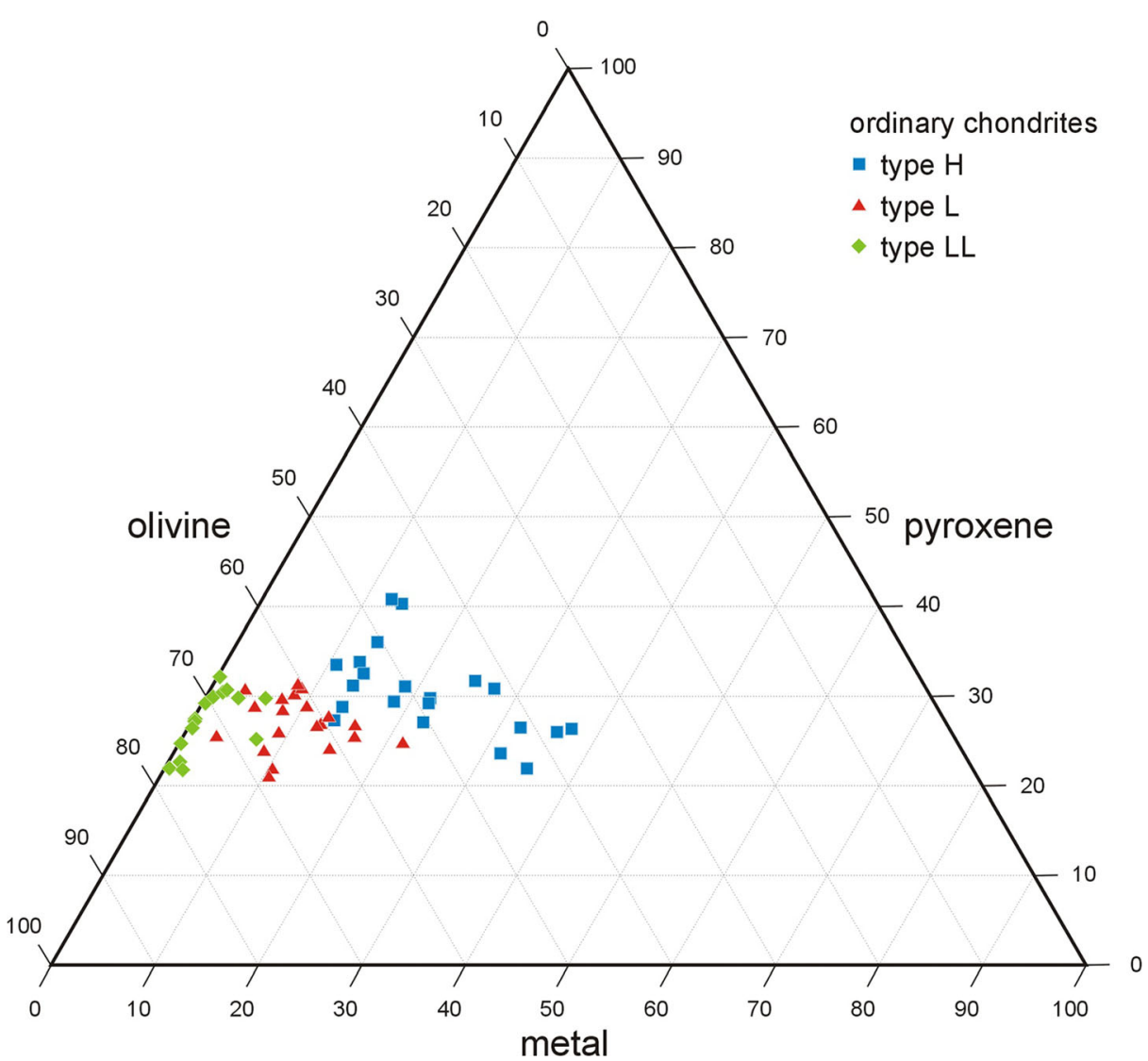

Fig. 5 The ternary plot of values assembled in our database for selected three parameters of Mössbauer spectra from Warsaw database 
Our results demonstrate that the meteorite Goronyo is of type $\mathrm{L}$ despite the fact, that in the Meteoritical Bulletin [20] it is attributed to type H. Additional measurements performed by Karwowski with the use of electron microprobe have further confirmed our determination of Goronyo's type [19].

\section{Discussion}

Review of the methods applied by four different Mössbauer laboratories for classification of ordinary chondrites led to the conclusion that forming an objective criterion is not easy (although differences between Mössbauer spectra were well seen).

The Mössbauer groups researching this area in Kanpur, Ekaterinburg and Canberra have been using qualitative methods, which relied on subjective determination of typical regions for ordinary chondrites type H, L or LL on type 2D or 1D plots. These plots demonstrated relationships between percentages of spectral areas associated with olivine, pyroxene, metallic phases or troilite.

In Warsaw group, we applied an objective, quantitative method that led to determination of the level of similarity of investigated meteorite to ordinary chondrite type H, L or LL. In this method, all four mineralogical phases (ol, pyr, met, tr) are applied simultaneously, as well as strong correlation between these variables is taken into consideration.

Each of the four scientific groups researching the application of Mössbauer spectroscopy for classification of ordinary chondrites have also applied different rules for their databases' construction. Ekaterinburg group included only their own measurements. The groups from Kanpur and Warsaw constructed their databases with the use of both their own and also of literature-derived results. The Canberra group on the other hand, have used the database from Kanpur for classification of the meteorite Lynch 001 (which they have previously measured and elaborated).

In our publication from 2018, we have explained the correctness of a procedure to include results of percentages of Mössbauer spectral areas obtained at different laboratories into the same database [12].

In the aforementioned publication, the measurement results for three ordinary chondrites obtained at two different Mössbauer laboratories were compared. The measurements were carried out with the use of different spectrometers. Additionally, three different fitting programs were applied. The comparison performed referred to distinctive assumptions for fitting procedure, such as establishing line intensities in sextets and taking in account the variable theta angle values while fitting troilite subspectra.

Below the abstract of this paper is cited:

"Comparing the results of Mössbauer spectroscopy investigation performed in two laboratories and at various conditions, we did not notice any systematics, which could support the hypothesis that instrumental factors or mode of fitting can influence the percentage of spectral areas. Differences in the percentages of spectral areas of the individual mineral phases were at the level of one percentage point. Therefore, there is no reason not to include results from different laboratories to the same database." 
For further verification, if the literature data and our own results can be included in the same database, we have constructed histograms presenting the percentages of the spectral areas of ol, pyr, met and tr for different types of ordinary chondrites, as obtained in our laboratory (white in Fig. 6) and as taken from the literature (gray in Fig. 6). As is demonstrated in Fig.6, both the data obtained in our laboratory, as well as the data obtained from literature, are grouping within the same regions. This has further validated the approach to include the literature data in our database.

\section{literature data \\ own data}

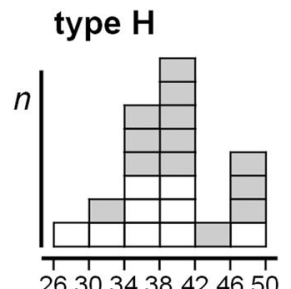

ol

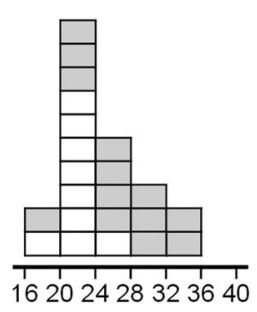

pyr

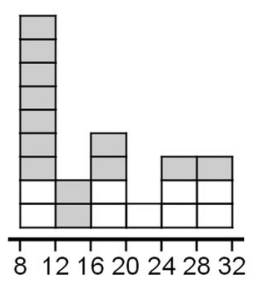

met

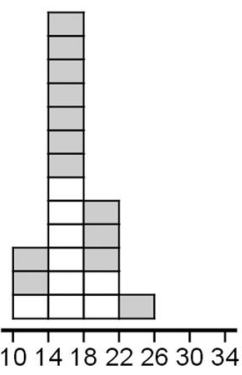

$\operatorname{tr}$

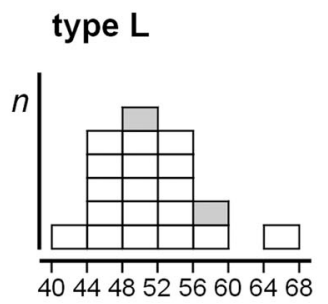

ol

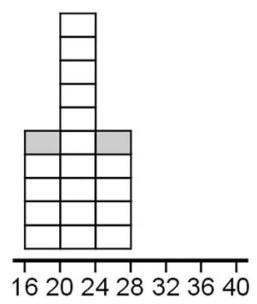

pyr

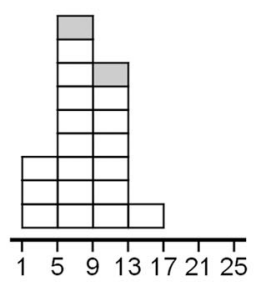

met

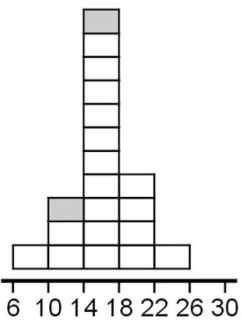

$\operatorname{tr}$

\section{type LL}

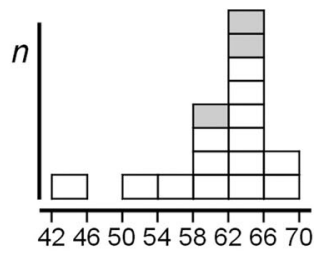

ol

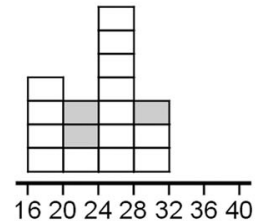

pyr

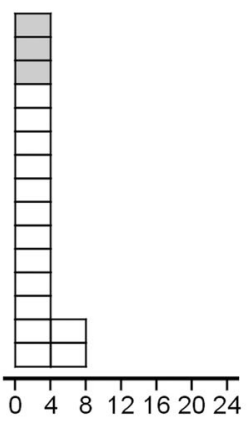

met

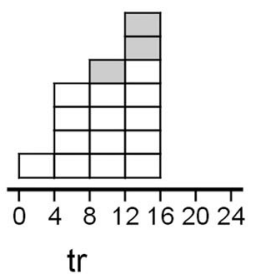

Fig. 6 Distribution of the percentages of Mossbauer spectral area associated with olivine (ol), pyroxene (pyr), metallic phase (met), troilite (tr) obtained in our laboratory (white rectangles) and taken from the literature (gray rectangles) for samples of ordinary chondrites type $\mathrm{H}$, type $\mathrm{L}$ and type LL; $\mathrm{n}$ - number of samples 
Databases of those scientific groups differed from each other in regard to levels of ferric iron. In ordinary chondrites ferric iron is the result of weathering (at first this is oxidation of metallic phases). The Kanpur group included in their database the Mössbauer spectra with the level of ferric iron between $0 \%$ to $11 \%$. The Ekaterinburg group included Mössbauer spectra with higher level of ferric iron (up to 28\%). The Canberra group used the database from Kanpur to classify the strongly weathered Lynch 001 meteorite (total level of ferric iron higher than 22\%). For the classification of little weathered meteorite Goronyo (level of ferric iron equal $2.3 \%$ ), the Warsaw group included in their database the Mössbauer spectra with level of ferric iron not higher than $7 \%$.

\section{Conclusions}

It is worth to stress that in each physical method, the investigated object should have the same properties as database, to which it is compared. For this reason, an approach to use the database from Kanpur for classification of the strongly weathered meteorite Lynch 001 was not scientifically sound, and other method should be attempted.

Database published by the Warsaw group is composed of 3 clusters (H, L and LL). Each cluster contains the information about percentages of spectra areas associated with olivine, pyroxene, metallic phases or troilite. This data was obtained for ordinary chondrites with small level of weathering (amount of $\mathrm{Fe} 3+\leq 7 \%$ ).

$4 \mathrm{M}$ method can currently be used for classification of ordinary chondrites with small level of weathering. However, we will be undertaking further research in order to extend the $4 \mathrm{M}$ method on ordinary chondrites with higher level of weathering.

When developing the application of 4M method on ordinary chondrites with higher levels of weathering, the differences in f-factor values for ferrous and ferric iron will have to be taken into consideration. The $4 \mathrm{M}$ method in its current developmental stage does not include the iron compounds with $\mathrm{Fe} 3+$.

Finally, we would like to stress that $4 \mathrm{M}$ method is universal, which means that ordinary chondrites measured and elaborated in all Mössbauer laboratories can be tested with its use.

Acknowledgments The authors would like to express their gratitude to Professor Israel Nowik.

Open Access This article is licensed under a Creative Commons Attribution 4.0 International License, which permits use, sharing, adaptation, distribution and reproduction in any medium or format, as long as you give appropriate credit to the original author(s) and the source, provide a link to the Creative Commons licence, and indicate if changes were made. The images or other third party material in this article are included in the article's Creative Commons licence, unless indicated otherwise in a credit line to the material. If material is not included in the article's Creative Commons licence and your intended use is not permitted by statutory regulation or exceeds the permitted use, you will need to obtain permission directly from the copyright holder. To view a copy of this licence, visit http://creativecommons.org/licenses/by/4.0/.

\section{References}

1. Knudsen, J.M.: Mössbauer spectroscopy of ${ }^{57} \mathrm{Fe}$ and the evolution of the solar system. Hyperfine Interact. 47, 3-31 (1989)

2. Paliwal, B.S., Tripathi, R.P., Verma, H.C., Sharma, S.K.: Classification of the Didwana-Rajod meteorite: a Mössbauer spectroscopic study. Meteorit. Planet. Sci. 35, 639-642 (2000) 
3. Verma, H.C., Rawat, A., Paliwal, B.S., Tripathi, R.P.: Mössbauer spectroscopic studies of an oxidized ordinary chondrite fallen at Itawa-Bhopji. India. Hyperfine Interact. 142, 643-652 (2002)

4. Verma, H.C., Jee, K., Tripathi, R.P.: Systematics of Mössbauer absorption areas in ordinary chondrites and applications to a newly fallen meteorite in Jodhpur. India. Meteor. Planet. Sci. 38, 963-967 (2003)

5. Prior, G.T.: The classification of meteorites. Mineral. Mag. 19, 51-63 (1920)

6. Mason, B.H.: The classification of chondritic meteorites. Am. Mus. Novit. 2085, 20 (1962)

7. Keil, K., Fredriksson, K.: The iron, magnesium and calcium distribution in coexisting olivine and rhombic pyroxenes in chondrites. J. Geophys. Res. Atmos. 69(16), 3487-3515 (1964)

8. Van Schmus, W.R., Wood, J.A.: A chemical-petrologic classification for the chondritic meteorites. Geochim. Cosmochim. Acta. 31(5), 747-765 (1967)

9. Oshtrakh, M.I., Petrova, E.V., Grokhovsky, V.I., Semionkin, V.A.: A study of ordinary chondrites by Mössbauer spectroscopy with high-velocity resolution. Meteorit. Planet. Sci. 43(5), 941-958 (2008)

10. Maksimova, A.A., Oshtrakh, M.I., Chukin, A.V., Felner, I., Yakovlev, G.A., Semionkin, V.A.: Characterization of Northwest Africa 6286 and 7857 ordinary chondrites using X-ray diffraction, magnetization measurements and Mössbauer spectroscopy. Spectrochim. Acta A Mol. Biomol. Spectrosc. 192, 275-284 (2018)

11. Elewa Nancy N. Cadogan J. M.: An 57Fe Mössbauer study of the ordinary chondrite meteorite Lynch 001. Hyperfine Interact. 238, 4 (2017)

12. Bogusz, P., Brzózka, K., Górka, B., Szumiata, T., Woźniak, M., Gałązka-Friedman, J.: Classification of meteorites - Mössbauer comparative studies of three ordinary chondrites measured in different conditions. Acta Phys. Pol. A. 134(5), 1070-1075 (2018)

13. Gałązka-Friedman, J., Szlachta, K., Karwowski, Ł., Woźniak, M.: Mössbauer studies of Soltmany and Shisr 176 meteorites - comparison with other ordinary chondrites. Hyperfine Interact. 226, 593-600 (2014)

14. Szlachta, K., Gałązka-Friedman, J., Woźniak, M.: Porównawcze badania mössbauerowskie meteorytów: Sołtmany (L6), Chelyabinsk (LL5) i Grzempy (H5) (Mössbauer comparative studies of the Sołtmany (L6), Chelyabinsk (LL5) and Grzempach (H5) meteorites). Acta Societatis Metheoriticae Polonorum. 5, 115-120 (2014)

15. Gałązka-Friedman, J., Woźniak, M., Duda, P., Rzepecka, P., Jakubowska, M., Karwowski, Ł.: Mössbauer spectroscopy - a useful method for classification of meteorites? Hyperfine Interact. 238, 11 (2017)

16. Gałązka-Friedman, J., Woźniak, M., Duda, P., Jakubowska, M., Bogusz, P., Karwowski, Ł.: Próby klasyfikowania chondrytów zwyczajnych przez zastosowanie spektroskopii mössbauerowskiej. Acta Societatis Metheoriticae Polonorum. 10, 23-28 (2019)

17. Jakubowska, M., Buczek, A., Gwiździel, K., Djellouli, A., Nowak, F., Woźniak, M., Gałązka-Friedman, J., Karwowski, Ł., Duda, P.: Badania mössbauerowskie trzech chondrytów zwyczajnych typu $\mathrm{H}$ i trzech chondrytów zwyczajnych typu LL - wyznaczanie niepewności powierzchni spektralnych. Acta Societatis Metheoriticae Polonorum. 10, 34-39 (2019)

18. Jakubowska, M., Czarnecki, A., Robak, M., Zagrobelna, A., Bogusz, P., Woźniak, M., Gałązka-Friedman, J., Karwowski, Ł., Duda, P.: Badania mössbauerowskie 3 chondrytów zwyczajnych typu L (Beni M'hira, Hyattville, Saratov) - wyznaczanie niepewności powierzchni spektralnych. Acta Societatis Metheoriticae Polonorum. 10, 29-33 (2019)

19. Woźniak, M., Gałązka-Friedman, J., Duda, P., Jakubowska, M., Rzepecka, P., Karwowski, Ł.: Application of Mössbauer spectroscopy, multidimensional discriminant analysis, and Mahalanobis distance for classification of equilibrated ordinary chondrites. Meteorit. Planet. Sci. 54(8), 1828-1839 (2019)

20. Koblitz J. MetBase. Meteorite Data Retrieval Software. Version 7.3 (CD-ROM), Ritterhude, Germany 1994-(2012)

Publisher's note Springer Nature remains neutral with regard to jurisdictional claims in published maps and institutional affiliations. 